\title{
Intravenous drug abusers attending an inner city accident and emergency department
}

\author{
R. M. MAKOWER, A. G. PENNYCOOK \& \\ C. MOULTON
}

Registrars in Accident and Emergency Medicine, Glasgow Royal Infirmary, Castle Street, Glasgow

\section{SUMMARY}

In a 3-month prospective study, intravenous drug abusers represented $1.14 \%$ of all new attendances at Glasgow Royal Infirmary. They generated a significant workload and were often difficult to identify. A very high proportion required surgery or other invasive procedures. The clinical and epidemiological characteristics of the patients were often unexpected. The risks to staff and other implications for the A\&E department are discussed.

\section{INTRODUCTION}

Despite much public health education and the devotion of increasing resources, intravenous drug abuse remains a significant problem, especially in the inner cities. Awareness of the risks involved in treating the increasing number of patients who abuse drugs has been highlighted in recent years, especially since the advent of HIV (Anonymous, 1990). A considerable number of such patients present to our accident and emergency department. Previous studies at Glasgow Royal Infirmary (Stone et al., 1989, 1990), have attempted to examine the problem retrospectively.

This prospective study set out to quantify the workload generated by intravenous drug abusers, to identify the conditions with which they present, and their subsequent management requirements. The epidemiological characteristics of this group of patients were also examined.

Correspondence: $\operatorname{Mr}$ R. Makozer. Accident and Energency Department, Kent and Canterbury Hospital, Canterbury CT1 3NG. 


\section{METHODS}

Over a 3-month period a questionnaire was inserted into all A\&E notes, to be completed by the doctor attending the patient. All patients were asked if they had ever used intravenous drugs.

If they answered positively the questionnaire was completed. The epidemiological information collected included their age, duration of drug abuse and age at first drug injection, postcode, registration and drugs used. The clinical data collected included the time of attendance, site of injection, diagnosis and subsequent management.

\section{RESULTS}

A total of 177 intravenous drug abusers attended on 215 occasions. This represented $1 \cdot 14 \%$ of the 18,849 new attendances in the study period. Of the 38 return visits 12 $(5.6 \%)$ were related to the initial condition.

The age distribution of the patients is shown in Fig. 1.

The age at which the patients first started injecting drugs, and the duration of their habit are shown in Figs 2 and 3.

The geographical distribution of the patients addresses by postcode, showed clustering which tended to correspond with the areas of greatest social deprivation.

A total of $140(65.1 \%)$ of patients were registered as drug abusers. Of the 75 not registered $34(45 \%)$ stated that they did not wish to be registered.

The number and types of drugs used are listed in Fig. 4 and Table 1. Eighteen patients $(8.4 \%)$ were in police custody. The distribution of the times of arrival are shown in Fig. 5. The sites of injection are listed in Table 2.

A total of $112(52 \cdot 1 \%)$ patients were admitted, $41(36 \cdot 6 \%)$ for specific surgical procedures. Their diagnoses and management details are given in Tables 3 and 4 .

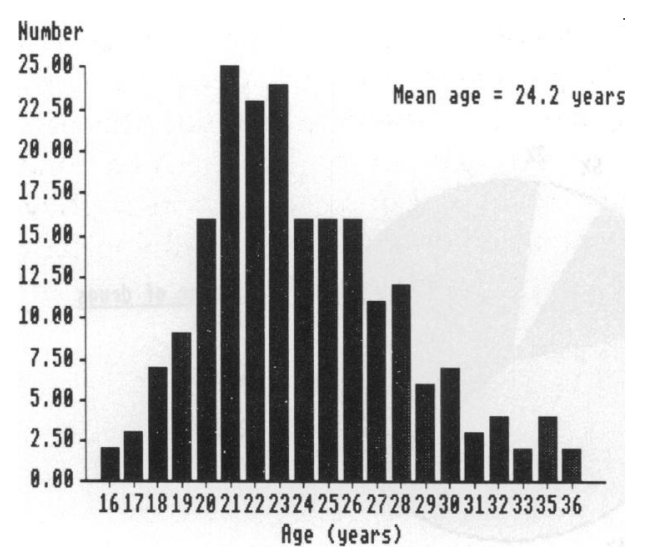

Fig. 1. Age distribution. 
R. M. Makower et al.

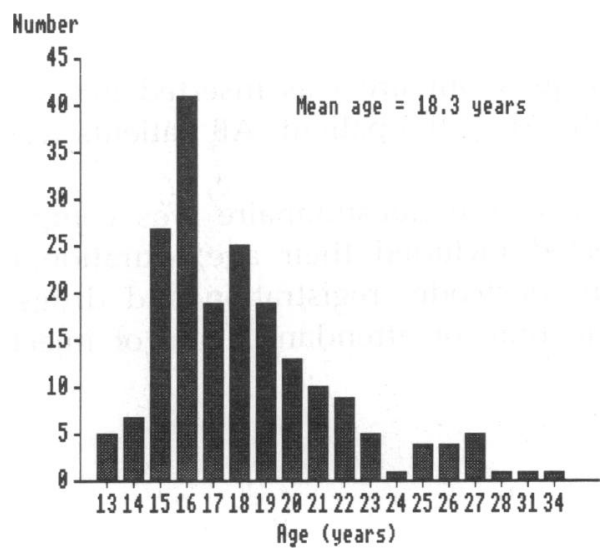

Fig. 2. Age at first injection.

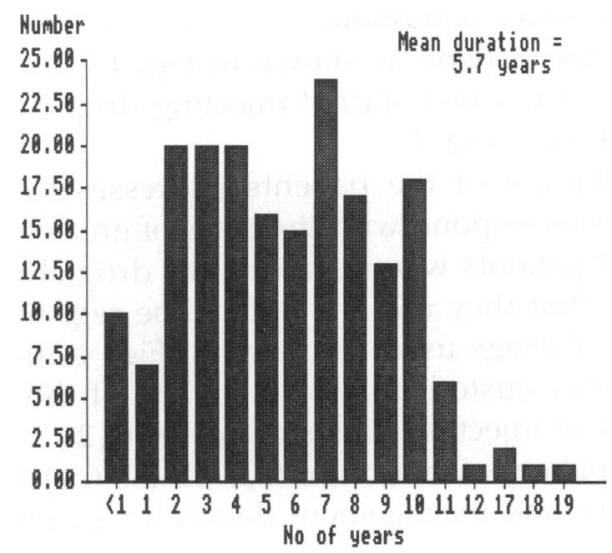

Fig. 3. Duration of habit.

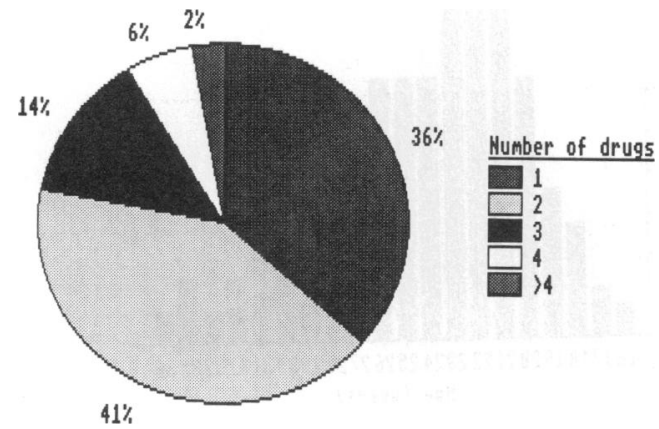

Fig. 4. Number of drugs used ( $2 \%,>4$ drugs; $6 \%, 4$ drugs; $14 \%, 3$ drugs; $36 \%, 1$ drug; $41 \%, 2$ drugs). 


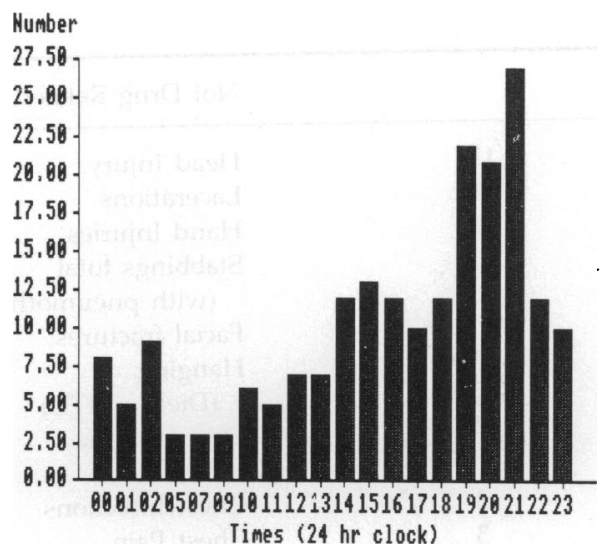

Fig. 5. Times of arrival.

Table 1. Frequency of use of individual drugs.

\begin{tabular}{lc}
\hline Drug used & No of patients \\
\hline Temgesic & 142 \\
Heroin & 120 \\
Temazepam & 105 \\
Diconal & 9 \\
Palfium & 8 \\
Amphetamines & 5 \\
Morphine & 4 \\
DF 118 & 2 \\
Valium & 1 \\
Triazolam & 1 \\
'Sulph' & 1 \\
Methadone & 1 \\
LSD & 1 \\
Pethadine & 1 \\
Cocaine & 1 \\
Distalgesic & 1 \\
\hline
\end{tabular}

Table 2. Sites of most recent injection.

\begin{tabular}{llr}
\hline Upper limb & & 107 \\
Antecubital & 35 & \\
Hand & 16 & \\
Unspecified & 56 & 83 \\
Lower Limb & & \\
Groin & 55 & \\
Feet & 10 & 8 \\
Unspecified & 18 & 17 \\
Neck & & \\
Not known & & \\
\hline
\end{tabular}


Table 3. Diagnoses.

\begin{tabular}{|c|c|c|c|}
\hline \multicolumn{2}{|l|}{ Drug related problems } & \multicolumn{2}{|l|}{ Not Drug Related } \\
\hline Abscesses: Groin & 13 & Head Injury & 11 \\
\hline Rupt. Aneurysm & 1 & Lacerations & 10 \\
\hline Other: L. Limb & 7 & Hand Injuries & 9 \\
\hline U. Limb & 22 & Stabbings total & 4 \\
\hline \multirow[t]{2}{*}{ Cellulitis } & 20 & (with pneumothorax) & 2 \\
\hline & & Facial fractures & 5 \\
\hline Opiate overdose & 17 & Hanging & 1 \\
\hline \multirow[t]{2}{*}{ Fits } & 11 & (Died on ITU) & \\
\hline & & Other trauma & 8 \\
\hline Deep Venous Thrombosis & 7 & & \\
\hline Phlebitis & 3 & Chest Infections & 3 \\
\hline \multirow[t]{2}{*}{ Vascular } & 3 & Chest Pain & 4 \\
\hline & & Oral Overdoses & 5 \\
\hline Hepatitis & 6 & Other medical & 11 \\
\hline Intraneural injection & 2 & & \\
\hline Broken Needle & 1 & Surgical problems & 8 \\
\hline Pancreatitis & 2 & & \\
\hline Drug Withdrawl & 3 & Intoxicated & 3 \\
\hline ?Infective endocarditis & 3 & & \\
\hline \multirow[t]{3}{*}{ ?Meningitis } & 3 & Orthopaedic problems & 3 \\
\hline & & Psychiatric & 2 \\
\hline & $124(58 \cdot 8 \%)$ & & $89(41.4 \%)$ \\
\hline Admissions & $81(65 \cdot 3 \%)$ & & $31(35 \cdot 6 \%)$ \\
\hline
\end{tabular}

Table 4. Management details.

\begin{tabular}{|c|c|c|c|}
\hline \multicolumn{4}{|c|}{ Admissions (Total 112 [52.1\%]) } \\
\hline A\&E wards & 59 & (30 for surgery') & \multirow{8}{*}{$36 \cdot 6 \%$ of admissions } \\
\hline Medical wards & 25 & & \\
\hline Surgical wards & 18 & (11 for surgery) & \\
\hline Orthopaedic & 2 & & \\
\hline Intensive care & 1 & (Died) & \\
\hline Psychiatric & 2 & & \\
\hline Infective diseases & 4 & & \\
\hline Maternity & 1 & & \\
\hline \multicolumn{4}{|c|}{ Discharges (Total 103 [47.9\%]) } \\
\hline Discharge no follow up & 65 & & \\
\hline Irregular Discharge & 20 & $(0.9 \%)$ & \\
\hline Narcan Reversal & 9 & & \\
\hline Discharge with appt & 9 & & \\
\hline
\end{tabular}

A total of $72.3 \%$ of all admissions were for problems directly attributable to intravenous drug abuse. 


\section{DISCUSSION}

This prospective study confirms that intravenous drug abusers generate a significant workload for the A\&E Department at Glasgow Royal Infirmary. Of total attendances $1 \cdot 14 \%$ represents approximately 900 consultations a year. The admission rate of $52.1 \%$ is considerably greater than the rate for all other attendances, and is double that reported in the previous study from this department (Stone et al., 1989). It is likely that there is a wide variation in the size of this problem between departments, even in the same city.

The patients seen were mostly in their early twenties (Fig. 1), and most had injected for less than 10 years. It is of concern that the most common age to start injecting is the mid to late teens, but the authors were disturbed by the finding that $20 \%$ of all intravenous drug abusers first experimented whilst still at school.

The clustering of patients' home addresses coincides with some of the most socially deprived areas of the city, strongly suggesting that, in Glasgow, intravenous drug abuse flourishes in conditions of socio-economic deprivation.

The fact that only $65.1 \%$ of patients were registered as drug addicts confirms the widely held suspicion that the official figures tend to underestimate the true prevalence of the problem. The legal requirement to register drug addicts in the face of their resistance, as shown by our figures ( $45 \%$ did not wish to be registered), places a potential strain on the doctor-patient relationship, and may jeopardize the clinical outcome.

The authors were surprised by the apparent widespread mixing of abused drugs, only $36.5 \%$ were regularly using the same drug (Fig. 4). Although Temgesic, Temazepam and Heroin were far more commonly abused than any other drugs, there were a total of 16 drugs named by different patients (Table 1). The wide pharmacological variation of drug types raises the possibility that the drug usage is a way of life rather than a true pharmacological dependency. Another factor in this variability may be a problem of street availability.

The small proportion of patients $(8.4 \%)$ who were in police custody did not seem excessive, in view of their likely dependency on petty crime to finance their habit. The irregular discharge rate of $0.9 \%$ is lower than anticipated in view of the previously reported level of $10 \%$ (Stone et al., 1989). This may reflect a better understanding of the needs of these patients, facilitating their access to clinical care.

The attendance times mirrored the standard pattern of peak attendances in the afternoon and evening (Fig. 5), refuting the popular belief that they present at more antisocial times than other patient groups.

The distribution of injection sites was perhaps predictable, but the authors are concerned by the high proportion $(31.8 \%)$ using major veins, especially in the groin and neck, with the associated risk of major vascular complications.

Nearly $60 \%$ of all presentations were directly related to the abuse of drugs. A total of $29.3 \%$ of these patients had infective conditions (abscesses and cellulitic reactions) related to the site of a recent injection. This is dissapointingly similar to the infection rate of $31 \%$ reported previously (Stone et al., 1990), prior to the widespread availability of needle exchange schemes. Another smaller group 
$(5 \cdot 6 \%)$ had systemic infections related to their habit. Overall infective conditions represented less than one third of all presentations, which is perhaps less than might be anticipated.

Of interest is the fact that $41.2 \%$ of conditions were not directly drug related (Table 3), but may be in part a reflection of the patient's life style. This group were less likely to require admission to hospital $(35.6 \%$ admission rate against $65.3 \%$ for drug-related problems) although a large proportion of both groups of patients required invasive procedures such as suturing or venepuncture.

Each of these invasive procedures exposes medical, nursing and other staff to the risk of infection by, in particular, HIV and Hepatitis B virus. Accidental needle stick injury is probably one of the greater risks (Astbury \& Baxter 1990, Anderson et al., 1991). Our study identified double the prevalence of drug abuse than the previous retrospective study (Stone et al., 1989). This, combined with the fact that many of our patients presented with non-drug related problems, and may not be immediately identifiable as 'high risk' patients, emphasizes the need to take protective measures to prevent contamination with serum. The recent recommendation from the Royal College of Surgeons (R.C.S. England, 1990) on pre-operative HIV testing cannot be applied in the A\&E department due to the immediacy of care required. In our view the use of gloves, eye protection, and the careful disposal of sharps and other contaminated material is imperative in the A\&E department.

Intravenous drug abusers present a significant health care need in the $A \& E$ department. They represent a risk to staff, especially in view of the difficulty in identifying a large proportion of them. Whilst this risk can be contained by the use of proper protective measures, and adequate staff awareness, the eventual aim must be to prevent future generations becoming drug-abusers. Our epidemiological data suggests that, to have the desired impact, this aspect of public health education must be aimed at children in their early teens (Fig. 2). The geographical clustering of the patients strongly suggests the need to attend to the socio-economic causes of intravenous drug abuse, for in the authors' view education alone is unlikely to be adequate. The data on the age of first injection of drugs suggest that this education should be targetted at, or before, the beginning of secondary school especially in those areas where intravenous drug abuse is most prevalent.

\section{REFERENCES}

Anderson D. C., Blower A. L., Ganguli L. A. \& Packer J. V. M. (1991) Preventing Needle Stick injuries. British Medical Journal 302, 769-770.

Anonymous. (1990) National Audit of drug misuse in Britain. Drug Misuse in Britain. ISBN 0948830859.

Astbury C. \& Baxter P. J. (1990) Infection risks in hospital staff from blood: hazardous injury rates and acceptance of Hepatitis B Immunisation. Journal of the Society of Occupational Medicine 40, 92-93.

Royal College of Surgeons of England (1990). Statement of AIDS and HIV infection.

Stone M. H., Stone D. H. \& McGregor H. A. R. (1989) Intravenous drug misusers presenting to the 
accident and emergency department of a large teaching hospital-a failure of clinical management? Scottish Medical Journal 34, 428-430.

Stone M. H., Stone D. H. \& McGregor H. A. R. (1990) Anatomical distribution of soft tissue sepsis sites in intravenous drug misusers attending an accident and emergency department. British Journal of Addiction 85, 1495-1496. 


\section{ERRATUM}

R. M. MAKOWER, A. G. PENNYCOOK \& C. MOULTON (1992) Intravenous drug abusers attending an inner city accident and emergency department. Archives of Emergency Medicine 9(1), 32-39.

The authors would like to correct the following error which appeared in Table 4 of the above paper.

In Table 4 the irregular discharge rate of 20 out of 215 attendances should have shown $9 \%$ instead of $0.9 \%$.

Table 4. Management details.

\begin{tabular}{|c|c|c|c|}
\hline \multicolumn{4}{|c|}{ Admissions (total 112 [52.1\%]) } \\
\hline A\&E wards & 59 & (30 for surgery) & \\
\hline Medical wards & 25 & & $36.6 \%$ of admissions \\
\hline Surgical wards & 18 & (11 for surgery) & \\
\hline Orthopaedic & 2 & & \\
\hline Intensive care & 1 & (Died) & \\
\hline Psychiatric & 2 & & \\
\hline Infective diseases & 4 & & \\
\hline Maternity & 1 & & \\
\hline \multicolumn{4}{|c|}{ Discharges (total 103 [47.9\%]) } \\
\hline Discharge no follow up & 65 & & \\
\hline Irregular discharge & 20 & $(9 \%)$ & \\
\hline Narcan reversal & 9 & & \\
\hline Discharge with appt & 9 & & \\
\hline
\end{tabular}

